\title{
AOSpine masters series volume 1: metastatic spinal tumors
}

\author{
AOSpine Masters Series, Vialle/Gokaslan/Boriani/Fisher. Publication Date: September \\ 2014, 1st Edition, 128 pp, 23 illustrations, Hardback, US\$ 99,99 EUR (D) 79,99 CHF \\ 112,00, ISBN (Americas): 9781626230460
}

\section{Pierre Kehr}

Received: 15 December 2014/ Accepted: 28 December 2014/Published online: 4 February 2015

(C) Springer-Verlag France 2015

This book is the first of a series which will comprise ten works which will allow a quasi exhaustive study of the state of the art in the treatment of the spine diseases. Stefano Boriano is the European guest to be only taken part in this work among many specialists as a large majority of North Americans and Canadian.

The evaluation and decision making for vertebral metastases are successively presented; the spinal instability of neoplastic origin; major complications of the radiotherapy; the resection en bloc; specific approaches according to the vertebral levels; the reconstruction and stabilization by osteosynthesis and fusion; the place of the minimally invasive surgery; the place of the vertebroplasty; complications of the surgery of vertebral metastases.

The work is largely illustrated, comprises many summary tables, and ends in an index making it possible to reach the various entries quickly.

It will have to appear in the library of any surgeon of the spine, whether it is confirmed or in formation.

Conflict of interest None.

P. Kehr $(\bowtie)$

Strasbourg, France

e-mail: pierre.kehr@gmail.com 